\title{
TWO CASES OF ADRENAL HYPERPLASIA WITH ADRENAL CORTICAL INSUFFICIENCY
}

\author{
BY \\ N. E. FRANCE and CATHERINE A. NEILL \\ From the Queen Elizabeth Hospital for Children, Hackney, London
}

(Received for Plblication february 9, 1950)

The adreno-genital syndrome in infancy is associated almost invariably with bilateral adrenal hyperplasia. The characteristic syndrome is a combination of hyperfunction of the genital hormones of the suprarenal, producing precocious virilism in males and pseudohermaphroditism in females, and hypofunction of the salt-water hormones resulting in an electrolyte imbalance of the Addisonian type. Glucose metabolism is usually unaffected. The condition has been frequently reported in two or more siblings. A general review of the subject has been written by Wilkins (1948).

There are numerous cases described in the literature of adrenal hyperplasia in older children or adults with sexual changes, but no symptoms of adreno-cortical insufficiency. We do not propose to discuss these further, although it would be of interest to know details of the progress in infancy of such cases.

Symptoms due to Adreno-cortical Insufficiency. The classical picture is of normal progress in the first week of life. The first symptom is usually vomiting, which may start at any time between one and six weeks, and is occasionally projectile in character. Several cases are recorded of laparotomy being performed for suspected pyloric stenosis or intestinal obstruction, and our second case was treated with pylostropin at one period. Associated with the vomiting there are usually small loose stools often containing mucus, marked lethargy, pyrexia, and frequently sweating. Dehydration appears early and is disproportionately great for the degree of vomiting. The symptoms are usually insidious in onset but become suddenly and dramatically worse, usually terminating in death between six and 12 weeks in untreated cases. The clinical picture is closely similar to that of Addison's disease, except that the glucose metabolism is usually normal (Wilkins, Fleischmann, and Howard, 1940; Jacobsen, Koepf, Talbot, and Wilkins, 1949). Pigmentation of the skin sometimes occurs (Butler, Ross, and Talbot, 1939; Wilkins et al., 1940). The clinical syndrome was first brought to general notice by Dijkhuizen and Behr in 1940, and since then fairly numerous reports have been made.

Biochemical Findings. Evidence that the symptoms were associated with low serum sodium and chloride levels and high serum potassium levels was provided by Butler et al. (1939) in a case later confirmed by laparotomy, and by Thelander and Cholffin (1941 and 1946) in a child who was kept alive till 6 years of age and died in an attack of measles. Two of the four cases recorded by Zuelzer and Blum (1949) had also had biochemical investigations. Cases with similar clinical and biochemical findings, where hyperplasia of the adrenals was probable but not proved, have also been reported (Darrow, 1943-4 Jacobsen et al., 1949). The largest group of cases are those not diagnosed during life and without biochemical investigation, but where the clinical history leaves little doubt that the symptoms were due to adreno-cortical insufficiency (Allibone, Baar. and Cant, 1947; Skelton, 1945; Blackman, 1946).

Cases with Adreno-cortical Insufficiency. The sexual changes are precocious development in boys and pseudohermaphroditism in girls. We give later the reasons for thinking that these changes are probably due to hyperplasia of the reticular zone. Only one definite case has been reported in a female with normal external genitalia (Dijkhuizen and Behr, 1940). Males usually appear normal at birth, but penile enlargement and sometimes pubic hair develop within a few weeks (Thelander and Cholffin. 1941 and 1946; Butler et al., 1939). Few investigations of the ketosteroid output have been recorded in these cases. Talbot, Albright, Saltzman. Zygmuntowitz, and Wixom (1947) in a male of 8 years found a urinary 17-ketosteroid output of about $200 \mathrm{mg}$., and an 11-oxycorticosterone level of 0.36. Darrow (1943-4) in a male of 6 months found a urinary 17-ketosteroid output of $2.5 \mathrm{mg}$. Zuelzer and Blum (1949) comment that it would be worth investigating the urinary hormones of the mother in these cases. Jacobsen et al. (1949) says 
that the maternal hormone output is normal but gives no references. Premature ossification of the carpal bones may occur (Wilkins et al., 1940 ; Darrow, 1943-4), but is not invariable and was absent in our first case and in two cases of Allibone et al. (1947). No radiographs were taken of our second case.

\section{Histology of the Normal Adrenal}

In the newborn child the adrenal cortex consists of three distinct zones: zona glomerulosa, zona fasciculata, and foetal reticular cortex. The last layer is the thickest and is composed of large lipoid-free cells resembling normal liver cells. Involution of this zone begins soon after birth and is often complete within two months of birth (Parkes, 1945) and certainly by the age of 1 year (Lewis and Pappenheimer, 1916). It is gradually replaced by the adult reticular cortex which is largely made up of granular eosinophilic cells containing lipoid but also including many cells with more deeply eosinophilic cytoplasm and hyperchromatic nuclei. Both types may contain brownish pigment.

Apart from the different arrangement of the cells in the various layers, it is possible to differentiate adult and foetal reticular tissue from each other and from the other zones by the characters of their individual cells. Even so, in the presence of hyperplasia of the cortex, there is frequently considerable difference of opinion as to which zone shows the greatest increase.

Grollman (1936) divides the cells of the cortex as a whole into two types: the interrenal cells, deficiency of which causes Addison's disease, and cells producing androgens. The differentiation of these cells is not satisfactory although Broster and Vines (1933) have claimed to distinguish androgenic cells by staining granules in their cytoplasm by the Ponceau-fuchsin technique. The specificity of this has been upheld by several observers (Allibone et al., 1947; Zuelzer and Blum, 1949), whereas others consider that it merely reflects the degree of eosinophilia and the lack of lipoids in the cytoplasm (Wilkins et al., 1940; Sudds, 1940; Flynn, 1942).

Functions of the Zones of the Cortex. Attempts have been made to identify the various zones with the production of specific hormones. Experiments on rats suggest that the zona glomerulosa produces a hormone influencing electrolyte and water regulation and probably closely allied to 11-desoxycorticosterone (Swann, 1940; Greep and Deane, 1947; Deane, Shaw, and Greep, 1948). These workers found that rats on a low sodium or a high potassium intake developed hypertrophy of the zona glomerulosa and shrinkage and disappearance of the ketosteroid droplets. They also found that the zona glomerulosa underwent shrinkage and atrophy if DOCA injections ( $2 \mathrm{mg}$. daily) were given for a month. There is some evidence that the zona fasciculata is the source of a hormone responsible for controlling carbohydrate, fat, and protein metabolism (Jacobsen et al., 1949).

It is now generally agreed that the reticular zone is the origin of the masculinizing hormones. This is borne out by the fact that virilism and hyperplasia of the reticular zone are frequently associated (Broster, Hill, and Greenfield, 1932; Goldzieher and Koster, 1935; Young, 1937; and others) and by the experimental work of Howard (1937). These hormones have an action similar to that of testosterone and are the probable precursors of the urinary 17-ketosteroids. They are not normally produced until about the eighth year of life.

\section{Gross Appearance and Histology of Adrenal Glands in Adrenal Hyperplasia}

In the adreno-genital syndrome the adrenal glands show gross enlargement due to thickening and duplication of the cortex. In the majority of cases the combined weight of the adrenals is $10-20 \mathrm{~g}$. although weights up to $34 \mathrm{~g}$. have been reported (Dijkhuizen and Behr, 1940). Aberrant hyperplastic cortical tissue has been frequently noted.

Histology. The interpretation of the histology of the hyperplastic cortex has led to several different conclusions. Wilkins et al. (1940) considered that the cortex in their case was distorted by the replacement of the normal zones by masses of androgenic cells of the prenatal reticular type. Blackman (1946) believed that there was hyperplasia of reticular cortex of adult type, and Allibone et al. (1947) found variations between different cases, some having a well-marked reticular zone of adult type and others a hyperplastic transient cortex. These findings suggest that both the foetal and adult types of zona reticularis produce androgens. A reticular cortex composed of cells of varying size and shape, including many bizarre giant cells, was observed by Dijkhuizen and Behr (1940). Although the majority of observers are agreed that the hyperplasia is on the part of the reticular cortex. either of adult or prenatal type, others have come to the conclusion that the zona fasciculata was thickened in the presence of a zona reticularis of normal size (Skelton, 1945: Zuelzer and Blum. 1949). The genital abnormalities indicate that excessive androgens are active as early as the eleventh to the twelfth week of foetal life. The anatomical development of pseudo-hermaphroditism due to excess androgens is well illustrated in the article of Jacobsen and his colleagues (1949). In view of the possible production of 
the electrolyte and water controlling hormone by the zona glomerulosa the histology of this zone in cases of hyperplasia with Addisonian crises assumes a greater interest. Occasional cases have been described in which the glomerular zone was thin or absent (Dijkhuizen and Behr, 1940; Skelton, 1945; Blackman, 1946) and this deficiency has been held to be the cause of the Addisonian crises. This view has been particularly upheld by Zuelzer and Blum (1949), who found the glomerular zone to be completely absent in four infants. However, a similar finding has been reported in adults with adrenal hyperplasia but without Addisonian symptoms (Blackman, 1946). Jacobsen et al. (1949) have pointed out that excessive production of a particular cortical steroid may partially cancel the physiological effects of others. The production of the hormone regulating salt and water metabolism may be normal but its effect may be inhibited by the presence of excess androgens, in which case a histological change in cells producing hormones other than androgens would be unlikely. On the other hand, it is conceivable that the adrenal may secrete a hormone causing excessive excretion of salt rather than its retention, as was suggested by the work of Lewis and Wilkins (quoted by Jacobsen et al., 1949). Changes in other endocrine glands are not striking. Involution of the thymus has been noted in many cases. It is, however, a common finding in infants dying after prolonged illness and is probably of little significance. The anterior pituitary may show a relative preponderance of basophil cells, but, in the absence of accurate cell counts, the significance of this finding cannot be assessed.

\section{Case Reports}

Our two cases were both female pseudohermaphrodites with Addisonian crises, but despite this they pursued very different clinical courses. Because we feel that the possible variations in the clinical course have not been sufficiently emphasized before, and think that there is a probable correlation between the clinical and histological patterns in the two cases, we are describing them in detail. The first case was diagnosed on the first day of life and energetic replacement therapy with salt and cortical extract was attempted after the first crisis, but control was never satisfactory and the infant died at 57 days. The second case was not diagnosed during life, and despite having only erratic amounts of saline at irregular intervals and no cortical extract, survived to 261 days. (The clinical diagnosis of this case was rendered much more difficult by the more insidious nature of the symptoms, the much less definite evidence of pseudohermaphroditism, and also by lack of facilities for biochemical investigation in the hospital in which she was treated.)

The two infants appear to represent two of many possible gradations between those cases of adrenal hyperplasia with electrolyte imbalance sufficiently fulminating to cause death in the first two weeks of life, and those where no evidence of electrolyte imbalance can be found.

Case 1 (R.H.). The infant was born at the Mothers Hospital, London, on February 9, 1949. Birth weight was 7 lb. 3 oz. (3,260 g.). Both parents were healthy and there was one normal female sibling aged 6 years. Family history, pregnancy, and labour were normal. In general appearance (Fig. 1) the infant was thin and worriedlooking from birth and had a fairly profuse growth of scalp hair. The skin never showed any pigmentation. The abnormal external genitalia (Fig. 2), which conform to the type frequently described, were noted at birth. and the infant was diagnosed as a female pseudohermaphrodite by Dr. Helen Mackay, who suggested that this might be a case of adrenal hyperplasia. The urethral orifice was in the position of perineal hypospadias and was very small, only admitting a No. 2 ureteric catheter. There was a blind dimple at the tip of the enlarged clitoris.

The pulse was regular and of good volume; the heart was not enlarged, and sounds were normal. The blood pressure was not taken before symptoms developed. All other systems appeared normal.

Progress. The infant seemed normally vigorous during the first week of life, and sucked well. The serum electrolyte levels at 6 days were normal (Serum $\mathrm{Na}, \mathrm{K}, \mathrm{Cl}$ and $\mathrm{HCO}_{3}$ ). At 7 days she developed pyrexia, loose stools, and some vomiting, and was treated by a 24-hour withdrawal of milk feeds. Vomiting. which was never projectile, persisted two to four times a day throughout life. For the next ten days there was slowly increasing lethargy, sweating, and slight pyrexia. These symptoms were not recognized as being due to adreno-cortical insufficiency, partly because of the normal biochemical findings at 6 days, and partly because pyuria was present. The pus cells probably came from the vagina, but a urinary infection was diagnosed and penicillin and sulphatriad given. A catheter specimen two days later was clear.

At 18 days the infant, who had been slowly deteriorating, became suddenly collapsed and dehydrated, and vomiting increased. The pupils were markedly contracted. A most dramatic improvement occurred following saline and eucortone therapy. Next day the infant seemed almost normal apart from some oedema and a soft systolic murmur which was heard irregularly thenceforward. Saline intake was reduced. and stopped at 27 days in an effort finally to establish that the symptoms were due to an electrolyte imbalance of the Addisonian type. Again there was slowly increasing lethargy, sweating, and dehydration.

The second crisis at $\mathbf{3 0}$ days was associated with low serum sodium and chloride levels, while the urinary 
Fig. 1.-Case 1, aged 42 days. Photograph showing general appearance; thin infant; worried expression; fairly profuse hair; slightly distended abdomen.

chlorides were $4 \mathrm{~g}$. per litre. Temporary improvement occurred with the administration of oral saline, but was not maintained.

The third crisis occurred at 41 days and eucortone was given again. At 42 days cardiac irregularity was noted for the first time, starting with inconstant 1:4 dropped beats, and progressing to gross coupled rhythm at 44 days. This crisis responded poorly to therapy, and at 43 days severe acidosis developed while the serum potassium remained high $\left(\mathrm{CO}_{2} 13 \cdot 1 \mathrm{~m} . \mathrm{eq}\right.$. litre; Cl 131.6 m.eq./litre; K 9.101 m.eq./litre; Na not done). Eucortone was stopped and saline intake reduced, and by 44 days the serum electrolyte levels were normal. Marked coupled rhythm persisted, shown by electrocardiography at 45 days to be due to alternate auricular extra-systoles (Fig. 3). Inconstant abdominal distension, sometimes gross, was noted from 41 days until death. Oral feeding was begun again. Saline intake was maintained at approximately $2 \mathrm{~g}$. per day. (The amount of $\mathrm{NaCl}$ given in the milk has been ignored throughout.) Percortin was substituted for eucortone and was given in a dose of $0.2 \mathrm{ml}$. per day. Slight improvement occurred and the cardiac rhythm became normal. At $\mathbf{5 0}$ days cardiac extra-systoles recurred, and there was some acidosis. and at 53 days the fourth crisis developed following a rise of serum potassium to 10.79 m.eq. (42 mg.) at 52 days. The blood pressure on this day was $90 / 60 \mathrm{~mm}$. mercury (right leg). Therapy was changed to eucortone $5 \mathrm{ml}$. four-hourly and intravenous saline was given. The infant became oedematous, acidotic, with low serum sodium and high potassium levels, and died at 57 days.

Other Investigations. Details of the biochemical

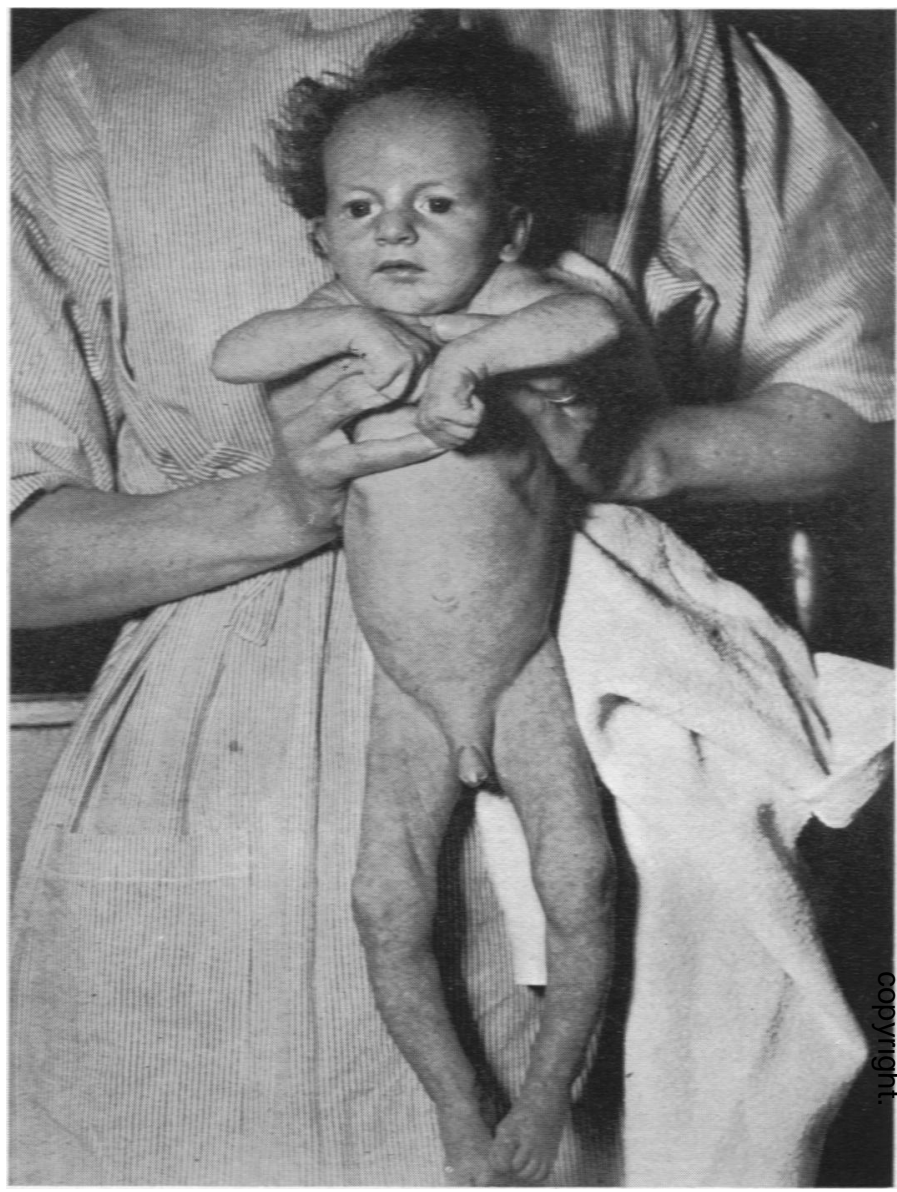

investigations are given in Table 1. A radiograph of the epiphyses taken after death showed no evidence of premature ossification of the carpal bones. The urinary ketosteroid level was not estimated owing to the great technical difficulty of obtaining a 24-hour specimen of urine.

The mother's urinary 17-ketosteroid output (estimated in January, 1950) was $12 \cdot 1 \mathrm{mg} . / 24$ hours. She is now pregnant again and we intend to do serial estimations during this pregnancy.

POST-MORTEM REPORT. Both adrenal glands occupied their normal position and were considerably enlarged (Fig. 4). The right gland weighed $6.0 \mathrm{~g}$. and the left $5.5 \mathrm{~g}$., their combined weight being $49 \%$ of the combined weight of the kidneys. Each gland was firm and uniformly grey in colour. The surface showed numerous fine corrugations together

Fig. 2.-Photograph (Case 1) showing corrugated labia resembling scrotal sacs, central median raphe, urethral orifice at base of enlarged clitoris, and blind dimple, resembling urethral orifice, at tip of clitoris. 

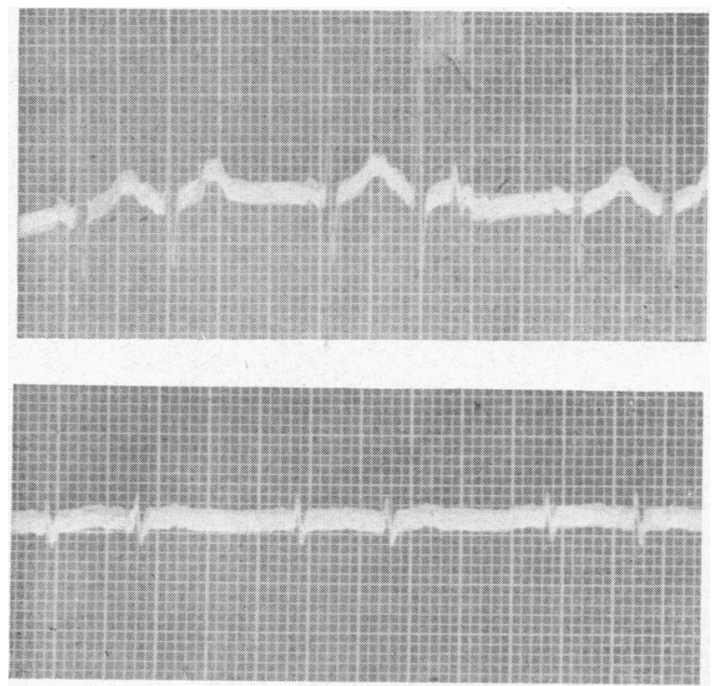

Fig. 3.-Electrocardiogram at 45 days showing coupling due to alternate auricular extra-systoles. (Leads I and CR IV only taken.)

with many small, round, pale nodules which projected above the general surface and measured up to $2 \mathrm{~mm}$. in diameter. On the cut surface the cortex showed prominent, duplicated convolutions and had an average thickness of $3-4 \mathrm{~mm}$. The medulla was mildly congested.

The thin, atrophic thymus weighed only $1.0 \mathrm{~g}$. The uterus $(2 \cdot 5 \mathrm{~cm}$. long) and the Fallopian tubes $(2 \mathrm{~mm}$. in diameter) were normal in size and configuration (Fig. 5) but the vagina opened on to the posterior wall of the urethra $1.0 \mathrm{~cm}$. above its external orifice by an aperture only $1 \mathrm{~mm}$. in diameter. The right ovary measured $2.2 \times 0.3 \times 0.2 \mathrm{~cm}$. and the left ovary $1.7 \times 0.3 \times 0.1 \mathrm{~cm}$. Although of normal length both were thinner than normal. Dorsal to the outer end of each ovary was a small, round nodule of adrenal tissue measuring $0.4 \mathrm{~cm}$. in diameter. There was no obvious prostate gland.

The foramen ovale of the heart was wide, but all other organs appeared normal.

Microscopy. The entire adrenal cortex (Fig. 6) was three to four times its normal thickness. The glomerular zone was thin and ill-defined and only in a few areas could a definite

Fig. 4.-Right adrenal (Case 1) showing convolutions of surface.

Fig. 5.- Internal genital organs (Case 1) showing opening of vagina into urethra. pseudoglandular arrangement of the cells be seen. Where present it was composed of cells with uniform round vesicular nuclei and slightly eosinophilic cytoplasm. In many places the glomerular zone was completely absent and here the columns of the fascicular zone tended to spread in rows lying parallel to the capsule. Although small islands of cortical tissue were present in the capsule there was no evidence of direct extension of the parenchyma through the capsule itself. Deep to the zona glomerulosa, and in places abutting on the capsule, was a thin, continuous layer of cells arranged mainly in columns at right angles to the surface and representing the zona fasciculata. These cells were regular in size and possessed vesicular nuclei and a finely granular, slightly eosinophilic cytoplasm.

The arrangement of the cells in the next and thickest zone varied in different parts of the gland. In some areas they were arranged in long parallel columns continuous with those of the fascicular zone, but elsewhere they had a reticular formation. Whatever the pattern, the component cells were the same. Three cell types could be identified. The majority resembled those of the more superficial cortex, but their cytoplasm was more eosinophilic and contained granules which were faintly stained by the Ponceau-fuchsin technique. Amongst these were many cells with vesicular nuclei, prominent nucleoli, and vacuolated cytoplasm containing coarse fuchsinophil granules. Finally there were scattered cells with dense nuclei and deeply eosinophilic cytoplasm similar to those found in the adult type of reticular cortex. These cells were more numerous in the outer part of the reticular zone, and it was here that the greatest fuchsinophilia was found. No pigment was present. In the deepest part of the cortex was a layer, 2-3 cells in thickness, representing the prenatal reticular cortex undergoing normal involution. Its cells were 
typical and quite distinct from those in the more superficial, adult type of reticular zone. The structure of the adrenal rests was identical to that of the adrenal cortex proper. The thymus gland showed crowding of the Hassall corpuscles, many of which were greatly enlarged and degenerate.

Sections of the pituitary gland were stained by Mann's methyl-blue-eosin technique and the cells counted in every third field of every third line. A differential cell count gave basophils $30.5 \%$; eosinophils $14 \cdot 8 \%$; chromophobe $54 \cdot 7 \%$ (total cells counted 16,230 ).

All other organs were normal.

Case 2 (C.R.). This infant (who was not seen by either of us during life) was born on August 9, 1948. Birth weight was $8 \mathrm{lb}$. $4 \mathrm{oz}$. $(3,747 \mathrm{~g}$.). She was the second child of healthy parents, the first being a normal boy. The external genitalia more closely resembled those of a male than did those of case I, the urethra being in the position of penile hypospadias. Although no testes were palpable, the infant was thought to be a male. No abnormality of any other system was found. She started vomiting when 8 days old, and had in all four crises characterized by pyrexia, vomiting, and lethargy. The stools were sometimes loose, but occasionally constipated. In one crisis pinpoint pupils were noted. The crises were treated empirically with saline with good but temporary response. The urinary chlorides were estimated only twice $(6 \mathrm{~g}$. per litre at 73 days and $4 \mathrm{~g}$. per litre at 108 days). Various diagnoses, including pyloric stenosis and gastro-enteritis, were considered, but the blood chemistry was not investigated and the infant died suddenly at 261 days, after she was apparently starting to do well.

POST-MORTEM Report. The right adrenal gland (Fig. 7) weighed $6.0 \mathrm{~g}$. and the left $7.0 \mathrm{~g}$., their combined weight being $33 \%$ of the combined weight of the kidneys. Their gross appearance was similar to that

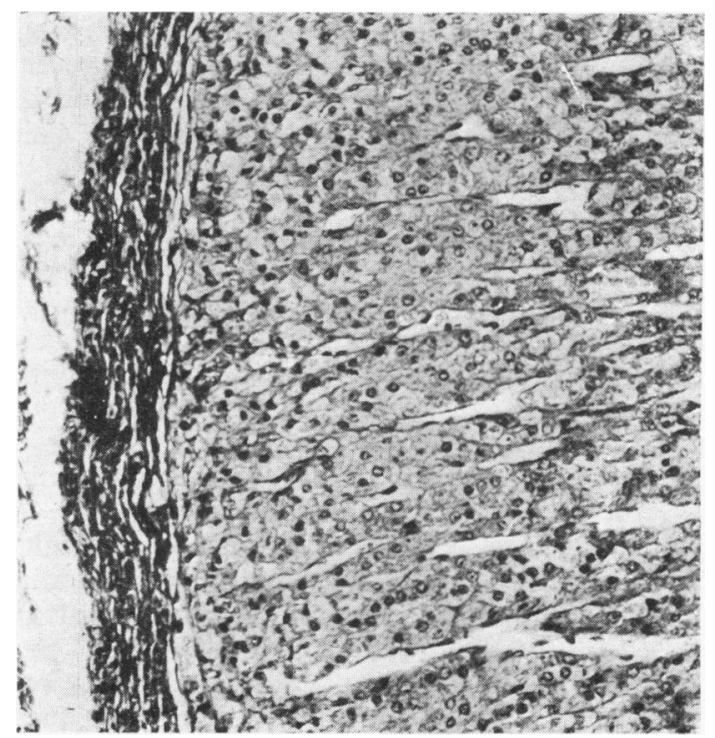

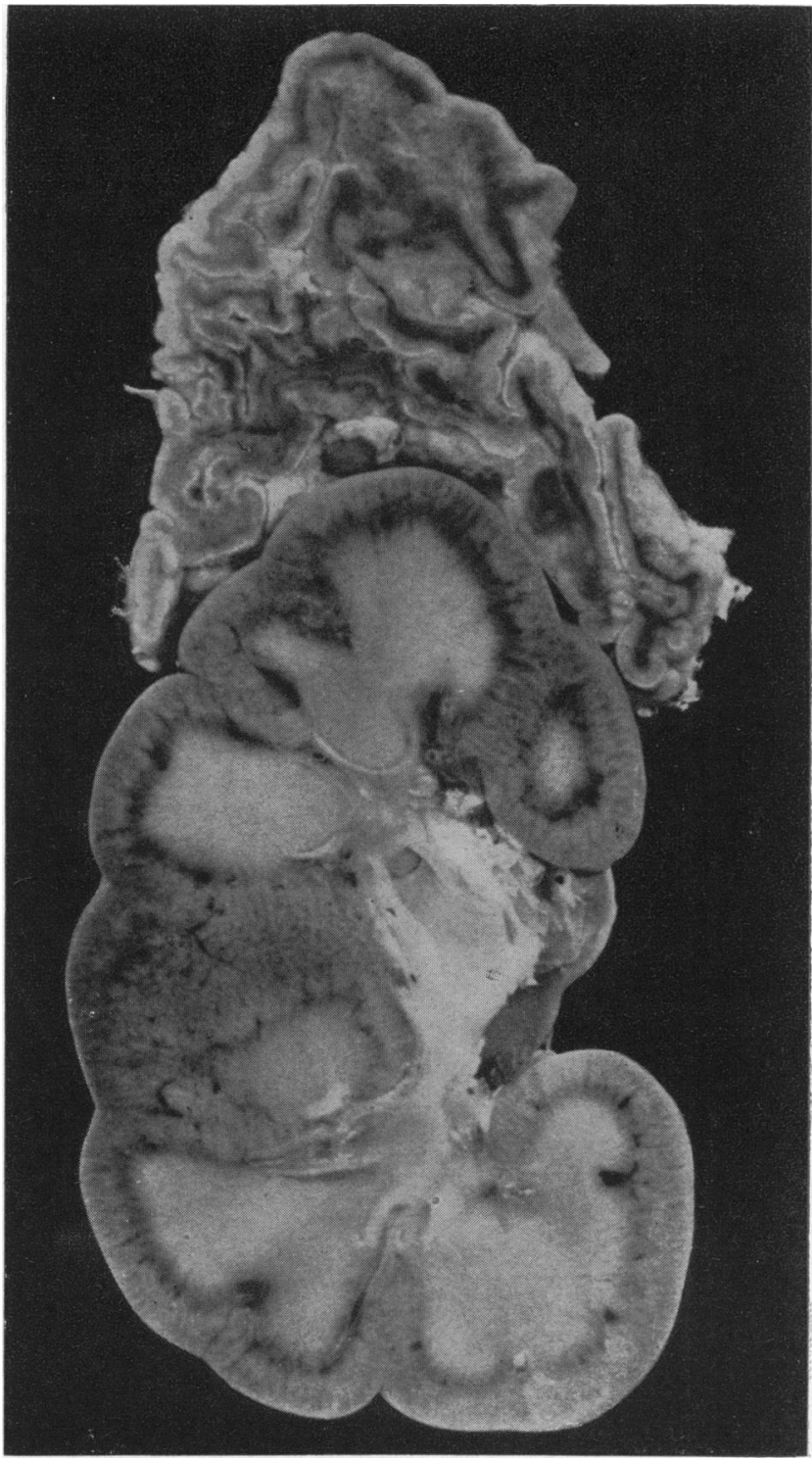

FIG. 7.-Right adrenal (Case 2) showing thickening and duplication of cortex. $\times 2$.

in Case I, but the hyperplasia and duplication of the cortex was more marked.

The thymus gland $(10.5$ g.) appeared normal. Although the uterus $(2 \cdot 3 \mathrm{~cm}$. in length) was of normal size, both Fallopian tubes were small with a diameter of less than $1 \mathrm{~mm}$. The vagina, $1.3 \mathrm{~cm}$. in length, had a diameter of $0.8 \mathrm{~cm}$. at the cervix but rapidly narrowed and opened on to the posterior wall of the urethra by an

Fig. 6.-Adrenal cortex (Case 1) showing absence of zona glomerulosa and portion of hyperplastic zona reticularis. Ponceau-fuchsin $\times 165$. 
orifice measuring $1 \mathrm{~mm}$. in diameter. Surrounding the upper parts of the urethra and vagina was a hard, pale mass of tissue which proved histologically to be prostatic tissue. The right ovary measured $2.0 \times 0.7 \times 0.3 \mathrm{~cm}$. and the left ovary $1.9 \times 0.6 \times 0.3 \mathrm{~cm}$. Lying in the right broad ligament between the Fallopian tube and the ovary were two adrenal rests each measuring $2 \mathrm{~mm}$. in diameter.

Microscopy. The adrenal cortex (Fig. 8) was about three times its normal thickness. The glomerular zone was thin and, although absent in a few places, it was much more obvious than in case I. In contrast, the fascicular zone was almost non-existent, the zona glomerulosa blending with the zona reticularis, which occupied about four-fifths of the total thickness of the cortex. In only a few areas were the cells of this zone arranged in parallel columns and even here the columns tended to anastomose. Only two types of cell could be distinguished. The greater number were of uniform size with vesicular nuclei and finely vacuolated, faintly eosinophilic cytoplasm. Here and there were smaller cells with denser nuclei and strongly eosinophilic cytoplasm in which vacuoles were less evident. These cells gave a strong fuchsinophil reaction. They were found in groups throughout the reticular zone, mainly in its superficial part. No pigment was present. There was no evidence of the foetal reticular cortex. The adrenal rests had a structure essentially the same as the cortex of the adrenals themselves.

A few Hassall corpuscles in the thymus gland were slightly enlarged and degenerate.

A differential cell count of the pituitary gland gave basophils $25 \cdot 6 \%$; cosinophils $13.9 \%$; chromophobes $60 \cdot 5 \%$ (total cells counted 18,623 ).

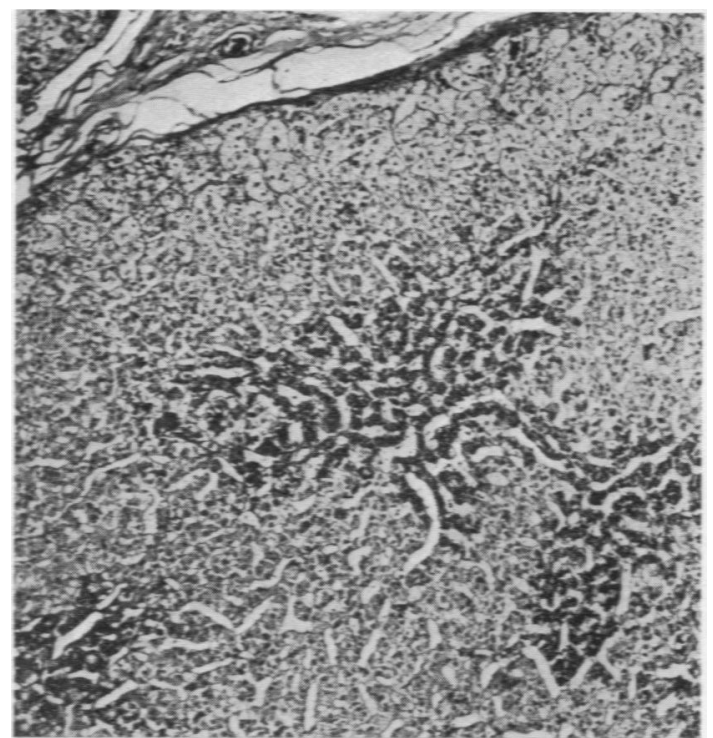

Fig. 8.-Adrenal cortex (Case 2) showing absence of zona fasciculata and groups of fuchsinophile staining cells in zona reticularis. Ponceau-fuchsin $\times 62$.
Both kidneys showed numerous small areas of calcification, identified as calcium by staining by the von Kossa technique. These were chiefly in the interstitial tissue of the cortex and beneath the epithelium of the second convoluted tubules where they produced distortion of the lumina. A smaller number of rather larger deposits were also present in the outer part of the medulla in relation to both the collecting tubules and the loops of Henle. Here and there they appeared to have broken through the tubular epithelium and were lying in the lumen itself. There was no inflammatory fibrous or foreign body reaction around the calcium. A striking feature was the marked fatty change of the loops of Henle.

All other organs were normal.

\section{Discussion}

Diagnosis and Treatment. In a female pseudohermaphrodite, or in an infant with a previous family history of adrenal hyperplasia, it is relatively easy to bear in mind the possibility of adrenocortical insufficiency. In a male infant before any sexual changes have developed the diagnosis is more difficult. The most characteristic clinical signs are vomiting, lethargy, and sweating, usually of insidious onset. These symptoms are common to many neonatal diseases, but an outstanding feature is the degree of lethargy and anorexia. If these symptoms suddenly lead to a profound collapse associated with dehydration, a subnormal temperature or hyperpyrexia, sometimes pinpoint pupils and small mucoid stools, the possibility of an Addisonian crisis should be considered. If a normal or high urinary chloride level is present despite the previous vomiting, and if the crisis responds dramatically to saline therapy, with or without cortical extract, the diagnosis becomes even more probable. Biochemical studies are, however. essential to confirm the clinical impression, and in a crisis low serum sodium and chloride and high potassium levels will be found in the presence of a relatively high urinary output of sodium and chloride. The serum chemistry may alter very rapidly from day to day, as can be seen from Table 1 , as also in cases of adrenocortical insufficiency from other causes. As in Addison's disease the serum sodium level is a much more sensitive guide to progress than the serum chlorides. One may expect similar but less marked biochemical changes in those cases where the progress of the disease is slow, as in our case 2 . Clinical diagnosis of these is particularly difficult. but the presence of persistent vomiting and feeding difficulty with periods of dehydration and persistent failure to thrive should lead to investigation of the serum and urinary electrolyte levels on several occasions. Jaudon (1946) has suggested that 
Tame 1

Analyses of Brochentcal Investigations in Case 1

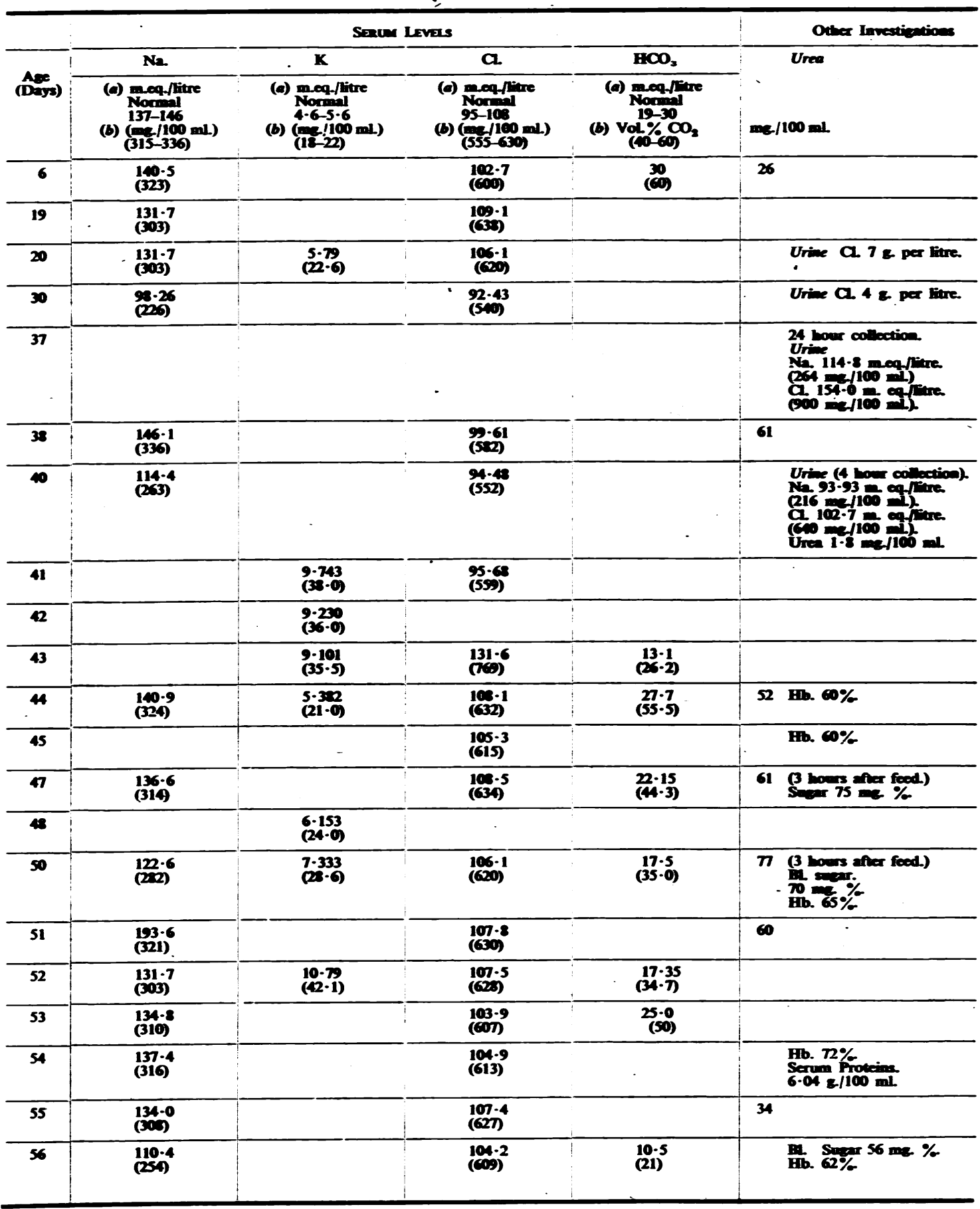


temporary adreno-cortical insufficiency in infancy may be an important cause of poor general progress, and may not always be associated with adrenal hyperplasia. This is an interesting possibility which requires further investigation.

Once diagnostic proof of adreno-cortical insufficiency has been provided by the blood chemistry, maintenance therapy should be attempted. Some patients can undoubtedly be kept alive with small or irregular quantities of saline, as in our second case, and in the patient of Wilkins et al. (1940) who had a 'craving for salt' and survived without therapy until 3 years of age. Others require a large regular intake of saline, e.g., Darrow's case (1943-4), which received $3 \mathrm{~g}$. $\mathrm{NaCl}$. daily before becoming stabilized satisfactorily. Opinions seem divided on whether to give some of the sodium as molar lactate or bicarbonate. This is probably unnecessary except in a crisis, when there is a danger of producing hyperchloraemic acidosis with saline alone. A similar finding is reported by Zuelzer and Blum in their (1949) case II. Cortical extract should certainly be given in a crisis. Although the dose does not appear to be established, by analogy with cases of Addison's disease, it is probably preferable to use crude cortical extract rather than percortin in a dosage containing at least $2-4 \mathrm{mg}$. a day of DOCA. This dosage can be reduced after 24 hours and the necessary maintenance dose found by trial and error. Some of these cases have been well stabilized by DOCA implants (Darrow, 1943-4) and others. The dangers of DOCA therapy are stressed by Jacobsen et al. (1949) and by Darrow (1943-4) who produced a crisis by giving DOCA without saline. The latter comments on the risk of producing cardiac symptoms and cardiac enlargement in adults with Addison's disease receiving DOCA therapy. In case 1 cardiac irregularity was a striking feature and there was an inconstant systolic murmur. In view of the known capacity of DOCA to produce myocardial damage, and even necrosis, it is possible that these symptoms were due to treatment, although "slow' or 'irregular' cardiac action has been recorded in cases which have received no treatment (Dijkhuizen and Behr's case 4, 1940; Zuelzer and Blum's case 4, 1949). It therefore seems possible that the cardiac irregularity was due to the toxic effects of the high serum potassium, although auricular extra-systoles are not apparently common in adults in Addisonian crises.

There is at present no known method of counteracting the effects of the excessive sex hormones. and virilism progresses. As yet no case of a female pseudohermaphrodite with Addisonian crises has been recorded as surviving beyond infancy, all the cases successfully treated being males (Butler et al..
1939; Thelander and Choffin, 1941; Jacobsen et al., 1949; Darrow, 1943-4). Jacobsen and his colleagues discuss the potential difficulties of later treatment of these cases as they approach puberty.

Correbation of Clinical and Histological Findings. Despite the occasional arrangement of the cells in parallel columns in our two cases, there was no doubt that the cells composing the hyperplastic zone corresponded to those of adult reticular tissue. In addition, however, large vacuolated fuchsinophil cells were diffusely scattered throughout the reticular zone of case 1 and large groups of fuchsinophil cells were present in case 2 . It was observed that those cells showing the most marked fuchsinophil reaction were also the most deeply stained with eosin. It appears unlikely that the whole of the adult reticular tissue was produced after birth and, as normally involuting foetal cortex was present in the first case, it is probable that both adult and foetal types coexisted during intra-uterine life.

The marked thinning of the glomerular zone in case 1 and its less marked deficiency in case 2 . where it was associated with almost complete absence of the zona fasciculata, suggest that this was related to the Addisonian attacks, especially in view of the fact that the first case was the more severe. However, the great increase in the surface area of the gland with the duplication of the layers of the cortex may, by spreading the zona glomerulosa, give a false impression of deficiency of that layer.

The significance of the renal changes in case 2 is difficult to assess. The salt-water hormone of the adrenal is thought to act chiefly by influencing electrolyte reabsorption in the loops of Henle. It is therefore a tempting hypothesis that deficiency of this hormone caused the fatty changes and calcification found in this area in case 2 . If this were so, however, one would expect similar findings in other cases and in Addison's disease in adults, whereas renal changes in Addison's disease are inconstant. Detailed histology of the kidneys has been reported in very few cases of the adrenogenital syndrome, and we have been unable to find any record of similar changes.

We thought it might be of interest to tabulate (Table 2) the chief clinical and histological findings in our two cases, as they appear to represent two clinical types of adreno-cortical insufficiency, case 1 being fulminating and case 2 subacute.

\section{Summary}

Two female pseudo-hermaphrodites due to bilateral adrenal hyperplasia are reported. The first case had severe Addisonian crises, biochemically 
TABLE 2

Comparison of Clinical and Histological Findings in Cases 1 and 2

\section{Case 1}

Frequent severe Addisonian crises requiring treatment with DOCA and saline.

Extra saline essential from 1st week of life.

Macroscopically: adrenal hyperplasia (6.0 and $5 \cdot 5$ g.).

Microscopically: zona glomerulosa grossly deficient, zona fasciculata normal, zona reticularis adult type. Diffuse fuchsinophil staining and vacuolation.

Kidneys normal.
Case 2

Less frequent 'crises' (biochemically not confirmed) responding to saline alone.

Period of fair growth without saline.

Adrenal hyperplasia (6.0 and $7 \cdot 0$ g.).

Zona glomerulosa moderately deficient, zona fasciculata grossly deficient, zona reticularis with groups of fuchsinophil cells. No abnormal vacuolation.

Kidneys showed calcium deposits in tubules and fatty change in loops of Henle. confirmed, but the second followed a more prolonged and less severe course. The evidence that the clinical differences between the two are associated with differences in the histological findings is presented. The possible significance of the recurrent cardiac irregularity in case 1 , and the histological changes in the renal tubules in case 2 , are discussed, and other cases of adreno-cortical insufficiency due to adrenal hyperplasia found in the literature are mentioned.

We should like to thank Dr. Helen Mackay and Dr. Ian M. Anderson for permission to publish these cases and for their kind advice and encouragement. We are also grateful to Dr. Winifred Young and Dr. B. Levin for their stimulus and advice. Dr. D. P. King performed the necropsy on case 2 and kindly allowed us to use material for photographs and sections. The biochemical investigations on Case 1 were done by Mr. T. P. Whitehead, A.R.I.C., and the histological preparations of both cases by Miss F. Humphries, A.I.M.L.T., and we wish to thank them both.

\section{REFERENCES}

Allibone, E. C., Baar, H. S., and Cant, W. H. P. (1947). Archives of Disease in Childhood, 22, 210.

Blackman, S. S. (1946). Bull. Johns Hopk. Hosp., 78, 180.

Broster, L. R., Hill, H. G., and Greenfield, J. G. (1932). Brit. J. Surg., 19, 557.

Cortex.' London.
Butler, A. M., Ross, R. H., and Talbot, N. B. (1939). J. Pediat., 15, 83.

Darrow, D. C. (1943-4). Yale J. Biol. Med., 16, 579.

Deane, H. W., Shaw, J. H., and Greep, R. O. (1948). Endocrinology, 43, 133.

Dijkhuizen, R. K., and Behr, E. (1940). Acta pediat. Stockh., 27, 279.

Flynn, R. (1942). Med. J. Aust., 2, 519.

Goldzieher, M., and Koster. H. (1935). Amer. J. Surg. 27, 93.

Greep, R. O., and Deane, H. W. (1947). Endocrinology: 40, 417.

Grollman, A. (1936). ' The Adrenals.' London.

Howard, E. (1937). Amer. J. Physiol., 119, 339.

Jacobsen, A. W.. Koepf, G. F., Talbot, N. B., and Wilkins, L. (1949). Pediatrics, 3, 515.

Jaudon, J. C. (1946). J. Pediat., 29, 696.

Lewis, R., and Wilkins, L. Referred to by Jacobsen.

Lewis, R. W., and Pappenheimer, A. M. (1916). J. med. Res., 34, 81 .

Parkes, A. S. (1945). Physiol. Rev., 25, 203.

Skelton, M. O. (1945). Archives of Disease in Childhood. $20,135$.

Swann, H. G. (1940). Physiol. Rev, 20, 493.

Sudds, M. V. N. (1940). Endocrinology, 26, 895.

Talbot, N. B., Albright, F., Saltzman, A. H., Zygmuntowicz, A., and Wixom, R. (1947). J. clin. Endocrinol., 7, 331.

Thelander, H. E., and Cholffin M. (1941). J. Pediat.. $18,779$. (1946). J. Pediat., 29, 213.

Wilkins, L. (1948). Advanc. Pediat., 3, 159.

Wilkins, L., Fleischmann, W., and Howard, J. E. (1940). Endocrinology, 26, 385.

Young, H. H. (1937). 'Genital Abnormalities. Hermaphroditism and Related Disorders . Baltimore.

Zuelzer, W. W., and Blum, A. (1949). J. Pediat., 35, 344. 